\title{
New Challenge for Hippocratic Database- Limited Disclosure
}

\author{
Pooja Sapra \\ Lecturer (CSE) \\ Apeejay College of Engineering \\ Vill. Silani, Distt. Sohna, Gurgaon
}

\author{
Minakshi Memoria \\ Lecturer (CSE) \\ Apeejay College of Engineering \\ Vill. Silani, Distt. Sohna, Gurgaon
}

\author{
Sunaina \\ Lecturer (CSE) \\ Apeejay College of Engineering \\ Vill. Silani, Distt. Sohna, Gurgaon
}

\begin{abstract}
With the exponential growth in data collection and number of users, the privacy preservation becomes the major issue in design and implement of various database system. Today the basic privacy solution is considered to be Hippocratic database. Our major concern is to get the solution of problems in LD of Hippocratic database. Hence we will formulate the basic privacy laws.

On the basis of there laws we will give a chain antology based model to get the solution of LD.

The full text of the article is not available in the cache. Kindly refer the IJCA digital library at www.ijcaonline.org for the complete article. In case, you face problems while downloading the full-text, please send a mail to editor at editor@ijcaonline.org
\end{abstract}

